\title{
Morphology and inner structure peculiarities of zircons from gabbro of Mid Atlantic Ridge (MAR)
}

\author{
TATIANA ZINGER ${ }^{1}$;
}

IPGG, RAS, Saint Petersbug, Russia; tzinger@mail.ru

Gabbros from the Mid Atlantic Ridge (MAR) contain three groups of zircon with different age: autocrysts, young xenocrysts, and old xenocrysts, the latter revealing crust recycling at the MAR (Bea et al., 2020). Additional proof of this process stems from zircon morphology and inner structure. Autocrysts (0.6 Ma - 1.7 Ma) are idiomorphic and show a narrow oscillatory zoning with lineations of micropores or voids marking the boundary between zones (Fig.1, grain S0664-26/62). This suggests the separation of a fluid phase during the magmatic evolution of the gabbro as a consequence of (i) temperature decrease during melt crystallization or (ii) decompression. Young xenocrysts Autocrysts and young xenocrysts (6.7 Ma to 17.6) show plastic deformations and recrystallization that partially obliterate the original zoning. Hydrothermal processes may also cause idiomorphic rims around recrystallized cores separated by voids bands mentioned before (Fig.1, grain S0981-12/24). This might be a result of a secondary decompression effect, which is an additional proof of recycling of previous MAR crust. The older xenocryst range from $200 \mathrm{Ma}$ to $3.2 \mathrm{Ga}$, and show various morphology and inner structures, always different from the other two groups. The lack of the voids and hydrothermal recrystallization indicate very short residence timed within the MAR gabbros, thus confirming short dwelling within hot MAR magmas.

Bea, F. et al. (2020). Lithos, 354-355, 105361

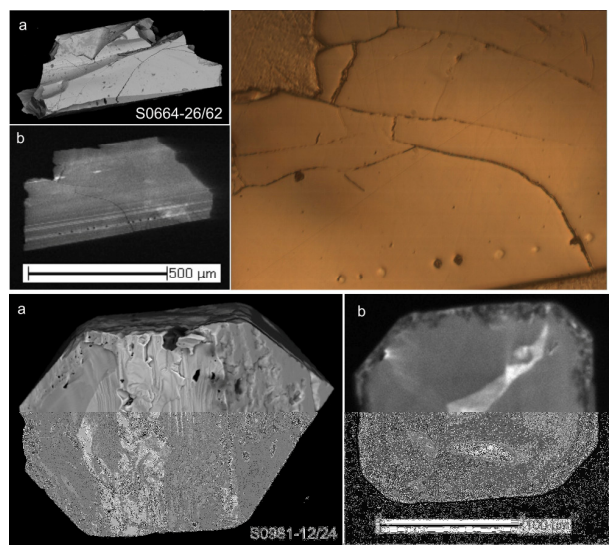

Fig.1. Zircons from gabbro of Vernadsky (S066426/45) and Doldrums (S0981-12/24) Fracture Zones. a) external forms, b) CL images 